\title{
DINÂMICA DA RELAÇÃO HIPSOMÉTRICA EM FUNÇÃO DA IDADE, DO SÍTIO E DA DENSIDADE INICIAL DE POVOAMENTOS DE BRACATINGA DA REGIÃO METROPOLITANA DE CURITIBA, PR ${ }^{1}$
}

\author{
Alexandra Consuelo de Plácido e Silva Bartoszeck ${ }^{2}$, Sebastião do Amaral Machado ${ }^{3}$, Afonso Figueiredo \\ Filho $^{4}$, Edilson Batista Oliveira ${ }^{5}$
}

\begin{abstract}
RESUMO - Esta pesquisa teve como objetivo analisar o comportamento e a dinâmica da curva hipsométrica em função dos fatores sítio, idade e densidade inicial em povoamentos de bracatinga (Mimosa scabrella Benth.), localizados na Região Metropolitana de Curitiba, PR. Os dados provieram da medição de diâmetros à altura do peito (DAP) e alturas totais em 20 parcelas permanentes remedidas quatro vezes da idade de 4 a 7,5 anos, em sítios de qualidades I, II e III, com densidades iniciais controladas para 2.000, 4.000 e 8.000 árvores/ ha, e as testemunhas, que em média apresentaram 25.000 árvores/ha no momento em que o experimento foi instalado. Inicialmente, um intenso trabalho de modelagem foi realizado (BARTOSZECK, 2000), ocasião em que foi selecionado o modelo de Curtis para se proceder às análises propostas no objetivo. A técnica de análise de co-variância foi, então, utilizada nas análises dos efeitos da idade, do sítio e da densidade sobre a curva de altura-diâmetro. Paralelamente foi feita a análise gráfica de todas as combinações possíveis, isto é, as quatro idades, três sítios e quatro densidades, usando-se o modelo de Curtis em cada combinação de fatores. Como resultados conclusivos obtidos através das análises de co-variância, detectaram-se efeitos estatisticamente significativos tanto da idade quanto do sítio sobre a relação hipsométrica. No entanto, o fator densidade não exerceu influência significativa sobre a mesma relação.
\end{abstract}

Palavras-chave: Mimosa scabrella, curva h/d, índice de sítio.

\section{DYNAMICS OF HIPSOMETRIC RELATIONSHIP AS A FUNCTION OF AGE, SITE AND INITIAL DENSITY IN Mimosa scabrella STANDS IN THE METROPOLITAN REGION OF CURITIBA, PR}

\begin{abstract}
The objective of this research was to analyse the behavior and the dynamics of hypsometric curves for age, site and initial density in native stands of bracatinga (Mimosa scabrella Benth), growing in the Curitiba Metropolitan Region. The data came from DBH and total height measurements of each tree in 20 permanent sample plots, remeasured 4 times from 4 to 7,5 years old, covering 3 different site classes and the initial densities of 2,000, 4,000, 8,000 and the control plots, with average 25,000 plants/ha. Basing on the same set of data Bartoszeck (2000) carried out an intensive research on modeling the height-diameter relation. Then the Curtis model, resulting in an equation for each combination of factors, was used to proceed
\end{abstract}

\footnotetext{
${ }^{1}$ Recebido para publicação em 19.3.2003 e aceito para publicação em 10.8.2004.

${ }^{2}$ UNIANDRADE. E-mail:<abartoszeck@ax.apc.org>.

${ }^{3}$ Universidade Federal do Paraná. E-mail:<sammac@floresta.ufpr.br>.

${ }^{4}$ Unicentro e Universidade Federal do Paraná. E-mail:<afonso@irati.unicentro.br>.

${ }^{5}$ Empresa Brasileira de Pesquisa Agropecuária, Centro Nacional de Pesquisa de Florestas.
} 
with the proposed analyses. Covariance analysis was used to examine the effects of age, site and initial density on the height-diameter curve. Graphic analyses were simultaneously done also for all possible combinations, that is, 4 ages, 3 sites e 4 densities, by using the equations resulting from the Curtis model for each factor combination. As conclusive results obtained through the covariance analysis, it was detected statistically significant effects for age as well as for site in the hypsometric relation. Conversely, the density factor did not have significant effect on the relation.

Key words: Mimosa scabrella, height-diameter relation, site index.

\section{INTRODUÇÃO}

Descrições com detalhes da espécie bracatinga (Mimosa scabrella Benth), contendo suas características, sua distribuição, seus usos, seu manejo tradicional e seu comportamento em geral, são encontradas em vários trabalhos, dentre os quais os de Carpanezzi et al. (1997), Baggio (1994), Tonon (1998), Bartoszeck (2000) e outros. Por essa razão e por motivos de espaço não se fazem comentários e descrições a esse respeito, e sim somente sobre o tema principal a ser abordado sobre os efeitos de alguns fatores na relação hipsométrica.

A relação hipsométrica mesmo em povoamentos de mesma idade varia com a qualidade do sítio e com a densidade. Em tais circunstâncias, uma única relação hipsométrica ajustada para todo o povoamento englobaria muitas relações diferentes, resultando em alta variabilidade em torno da linha de regressão da altura sobre o diâmetro (PRODAN et al., 1997). Por isso, um procedimento usado em inventários florestais para solucionar esse problema tem sido ajustar equações independentes para cada unidade amostral ou, então, para cada grupo homogêneo de parcelas em termos de idade, sítio e densidade. Dependendo dos fatores considerados, a curva dessa relação pode variar quanto à forma, inclinação e origem (intercepto).

A forma da curva pode fornecer uma indicação sobre o desenvolvimento e fase de crescimento do povoamento florestal: inclinação íngrime indica, normalmente, um povoamento jovem que ainda está em franco desenvolvimento e inclinação achatada, povoamentos mais velhos, onde o incremento corrente anual, principalmente em altura, está em declínio. Com o passar do tempo, curvas de altura/diâmetro do mesmo povoamento, porém construídas em idades diferen- tes, tendem a se deslocar para cima e para a direita, tornando-se cada vez mais aplainadas com o avanço da idade (CURTIS, 1967; CARDOSO, 1989; MACHADO et al., 1993, 1994; BARTOSZECK, 2000).

Deve-se considerar que a inclinação da curva hipsométrica é determinada pelo crescimento relativo dos diâmetros e das alturas das árvores que compõem o povoamento. No momento em que o povoamento florestal atingir seus valores assintóticos, tanto em altura quanto em diâmetro, a curva hipsométrica vai se alterar muito pouco. No caso de florestas clímax, como a floresta amazônica, essa curva é mais ou menos estável ao longo do tempo, conforme mencionado por Machado et al. (1994). Avaliando a influência da idade sobre a curva hipsométrica, Cardoso (1989) constatou forte efeito, tanto sobre os coeficientes $b_{0}$ (intersecção) quanto sobre as inclinações das linhas de regressão (coeficientes $b_{1}$ ).

No que se refere ao sítio, a inclinação da curva hipsométrica é normalmente mais acentuada em locais menos produtivos. Nesse sentido, Cardoso (1989) em Pinus taeda e Machado et al. (1994) em Pinus elliottii verificaram haver forte efeito do sítio somente sobre o coeficiente de intersecção das linhas de regressão na maioria das classes de idade de plantações, sendo as linhas crescentes do pior para o melhor sítio e, portanto, estatisticamente paralelas entre si $\left(\right.$ mesmo $\left._{1}\right)$.

Ao analisar o fator densidade sobre a relação hipsométrica, deve-se considerar o seguinte: diversas pesquisas, dentre as quais a de Tonon (1998) com povoamentos de bracatinga, indicaram que a densidade, seja ela inicial, seja atual, exerce forte efeito sobre o crescimento do diâmetro das árvores que compõem o povoamento, porém pouco ou quase nenhum efeito sobre o crescimento em altura, especialmente o das árvores dominantes. 
Então, por ser a bracatinga uma espécie importante, notadamente para a região metropolitana de Curitiba, e por existir carência de estudos a seu respeito sobretudo quanto aos seus aspectos biométricos, é que se realizou esta pesquisa. Seu objetivo foi avaliar os efeitos dos fatores idade, sítio e densidade inicial acerca das curvas de relação hipsométrica, usando a técnica de análise de co-variância para testar tanto o paralelismo quanto os interceptos das equações resultantes.

\section{MATERIAL E MÉTODOS}

\subsection{Localização e caracterização da área de estudo}

Os dados para a realização do presente trabalho provieram de 20 parcelas permanentes instaladas em bracatingais nativos localizados em diferentes propriedades, nos municípios de Colombo e Bocaiúva do Sul, norte da região metropolitana de Curitiba.

O tipo climático da região é o $C f b$, segundo a classificação de Köppen, o qual corresponde ao clima temperado propriamente dito, mesotérmico úmido, com quatro estações bem definidas, com verões quentes e chuvosos e invernos frios, com períodos secos eventuais. A temperatura média anual fica em torno de $17^{\circ} \mathrm{C}$, com médias das mínimas de $12^{\circ} \mathrm{C}$ e das máximas de $23^{\circ} \mathrm{C}$; acontecem entre 10 e 25 geadas por ano (MAACK, 1981; IAPAR, 1994).

A precipitação média anual dos municípios onde se encontram as parcelas permanentes situa-se em torno dos $1.400 \mathrm{~mm}$, com umidade relativa do ar de $80 \%$. As precipitações máximas ocorrem, normalmente, nos meses de janeiro (200 mm) e as mínimas (75-100 mm/mês), entre abril e agosto (MAACK, 1981; IAPAR, 1994).

Os solos predominantes da região são os Cambissolos, com diferentes graus de profundidade e fertilidade. Em geral são solos pobres, pouco desenvolvidos e dispostos em um relevo bastante ondulado, com inclinações diversas. São solos ácidos, com elevadas concentrações de alumínio e baixa saturação de bases. Predominam as texturas argilosas e ricas em matéria orgânica no horizonte A, apresentando boa drenagem (BAGGIO, 1994; CARPANEZZI, 1997). A altitude varia em torno dos $900 \mathrm{~m}$ acima do nível do mar.

\subsection{Base de dados}

A base de dados advém de um experimento de densidade inicial, desenhado em blocos ao acaso, planejado e executado pelo pesquisador Antonio A. Carpanezzi. Esse experimento foi instalado em bracatingais nativos, regenerados sob o sistema tradicional de manejo usado pelos proprietários rurais há mais de 60 anos. Foram instalados cinco blocos em quatro diferentes propriedades, com redução da densidade inicial para $2.000,4.000,8.000$ e as testemunhas, que em média se mantiveram com aproximadamente 25.000 plantas por hectare, no momento da instalação, com um ano de idade.

Foram, então, implantadas 20 parcelas de $13 \times 25$ $\mathrm{m}\left(325 \mathrm{~m}^{2}\right)$, deixando ainda uma faixa de bordadura de $5 \mathrm{~m}$ em volta de cada uma delas. No momento de se fazer o raleio, por ocasião da implantação do experimento, procurou-se, de modo geral, retirar as árvores menores das parcelas.

A medição das alturas de toda a árvore e a contagem das árvores iniciaram-se desde o primeiro ano de vida do povoamento. No entanto, a inclusão da medição de diâmetros à altura do peito (d) começou apenas por volta dos quatro anos de idade, com medição em torno das idades de 4,0; 5,1; 6,3; e 7,5 anos. Por essa razão, as relações hipsométricas só puderam ser desenvolvidas nessas idades especificadas. Além disso, deve-se ressaltar que as alturas foram medidas com varas telescópicas e os diâmetros, com sutas.

A classificação de sítio após as medições foi baseada na pesquisa de Machado et al. (1997), rearranjada por Tonon (1998). Após o trabalho com os dados, verificou-se que um dos blocos se incluiu na classe de sítio $\mathrm{I}$, o que significa $16,8 \mathrm{~m}$ de altura dominante à idade de referência de sete anos; dois blocos se incluíram na classe II $(13,5 \mathrm{~m})$ e dois na classe III $(10,2 \mathrm{~m})$.

\subsection{Análise dos efeitos dos fatores sobre as linhas de regressão}

Em uma primeira fase da pesquisa de Bartoszeck (2000) foram realizados exaustivos testes e ajustes de modelos para a função hipsométrica, tendo em vista a existência de dados em quatro densidades, três sítios e diversas idades entre 3,9 e 7,6 anos. Nesta pesquisa foram testados 12 modelos, tradicionalmente encontrados na literatura florestal, mais sete modelos, denominados genéricos, por incluírem variáveis

R. Árvore, Viçosa-MG, v.28, n.4, p.517-533, 2004 
independentes referentes ao povoamento, como altura dominante, idade, densidade, diâmetro quadrático etc. Ao todo foram mais de 500 análises envolvendo a combinação dos modelos com os fatores sítio, idade e densidade.

Para se avaliar a evolução das curvas hipsométricas em função dos fatores sítio, idade e densidade, primeiramente foram construídas as curvas de altura sobre diâmetro usando as equações resultantes do modelo de Curtis, as quais foram ajustadas por Bartoszeck (2000), na sua forma linearizada:

$$
\ln h=b_{0}+b_{1} \frac{1}{d}
$$

em que:

$$
\begin{aligned}
& h=\text { altura total }(\mathrm{m}) ; \\
& d=\text { diâmetro à altura do peito - DAP }(\mathrm{cm}) ; \\
& b_{0}, b_{1}=\text { coeficientes estimados; e } \\
& \ln =\text { logaritmo neperiano. }
\end{aligned}
$$

O modelo foi ajustado pela técnica de regressão linear simples nas diversas combinações, a fim de verificar, graficamente, o comportamento destas através da análise visual. Ao se analisar o efeito, por exemplo da idade, mantiveram-se tanto o sítio quanto a densidade constantes. O mesmo procedimento foi seguido no momento de analisar os efeitos dos outros fatores, em uma tentativa de evitar efeitos colaterais.

Embora a comparação visual entre linhas de regressão seja um expediente desejável, sempre é recomendada a aplicação de um teste analítico para a obtenção de resultados conclusivos e não subjetivos sobre as diferenças ou efeitos entre as diversas equações resultantes do ajuste dos modelos nas diversas situações. Então, para comparação decisiva entre as linhas de regressão e avaliação dos efeitos da idade, do sítio e da densidade sobre a curva hipsométrica, bem como da significância dos efeitos, foi utilizada a análise de co-variância, através dos testes de paralelismo e coincidência.

Os resultados das análises de co-variância desses testes foram avaliados através do teste F, cujos valores calculados foram comparados com os tabelados, tanto no nível de $1 \%$ quanto no de $5 \%$ de significância $(\alpha=0,05$ e $\alpha=0,01)$. O teste usado foi descrito em detalhes por Freese (1970) e utilizado por di- versos outros autores, para a comparação de equações de regressão (FIGUEIREDO FILHO, 1983; OLIVEIRA et al.,1990; AZEVEDO et al., 1999).

As equações de regressão podem diferir por terem diferentes inclinações. Existindo o paralelismo, elas podem diferir em nível, ou seja, seus interceptos não são iguais (KOZAK, 1972). Ao fazer testes para detectar se ocorrem regressões comuns, o procedimento consiste, primeiro, em se verificar se há inclinações comuns. Se as inclinações diferem significativamente, as regressões são diferentes e não é necessária a continuidade dos testes. No entanto, se as inclinações são significativamente diferentes, testa-se a diferença em posição, ou seja, dos interceptos (FREESE, 1970). Essa seqüência metodológica foi executada nesta pesquisa.

\section{RESULTADOS E DISCUSSÕES}

\subsection{Análise do fator idade na relação hipsométrica}

Após a escolha do modelo de Curtis foram traçadas graficamente as linhas de regressão das idades de 3,9 e 4,8 anos na classe de sítio I; idades de 4,$1 ; 5,0 ; 6,3$; e 7,5 anos na classe de sítio II; e idades de 4,$2 ; 5,4 ; 6,3$; e 7,6 anos na classe de sítio III, todas pertencentes às parcelas permanentes. A evolução das curvas de relação hipsométrica $(h / d)$ foi mais íngreme nas idades iniciais, suavizando e deslocando-se, ligeiramente, para cima e para a direita ao longo do tempo, como se pode observar na Figura 1.

Resultados similares foram encontrados por Crechi (1996), em Araucaria angustifolia, em que, à medida que aumenta a idade, as curvas que descrevem a relação altura-diâmetro deslocam-se para cima e para a direita, acompanhando o crescimento em diâmetro e altura, sendo as curvas nas idades jovens mais íngremes em relação às curvas nas idades mais velhas.

Pode-se visualizar, na Figura 2, certa distância entre as curvas da relação altura-diâmetro com o efeito da idade nos tratamentos de densidade inicial de 2.000 e 4.000 árvores/ha. Já nas densidades-testemunha e 8.000 árvores/ha, as curvas estão muito próximas, indicando não haver diferença significativa, visto que o intervalo entre as medições foi de apenas um ano. A análise de co-variância comprova a sugestão dessas curvas, conforme consta no Quadro1, em que se pode visualizar o procedimento de como foi obtido o valor de $F$ nos testes de inclinação e intercepto a 1 e $5 \%$ de significância. 
Dinâmica da relação hipsométrica em função da idade, ...
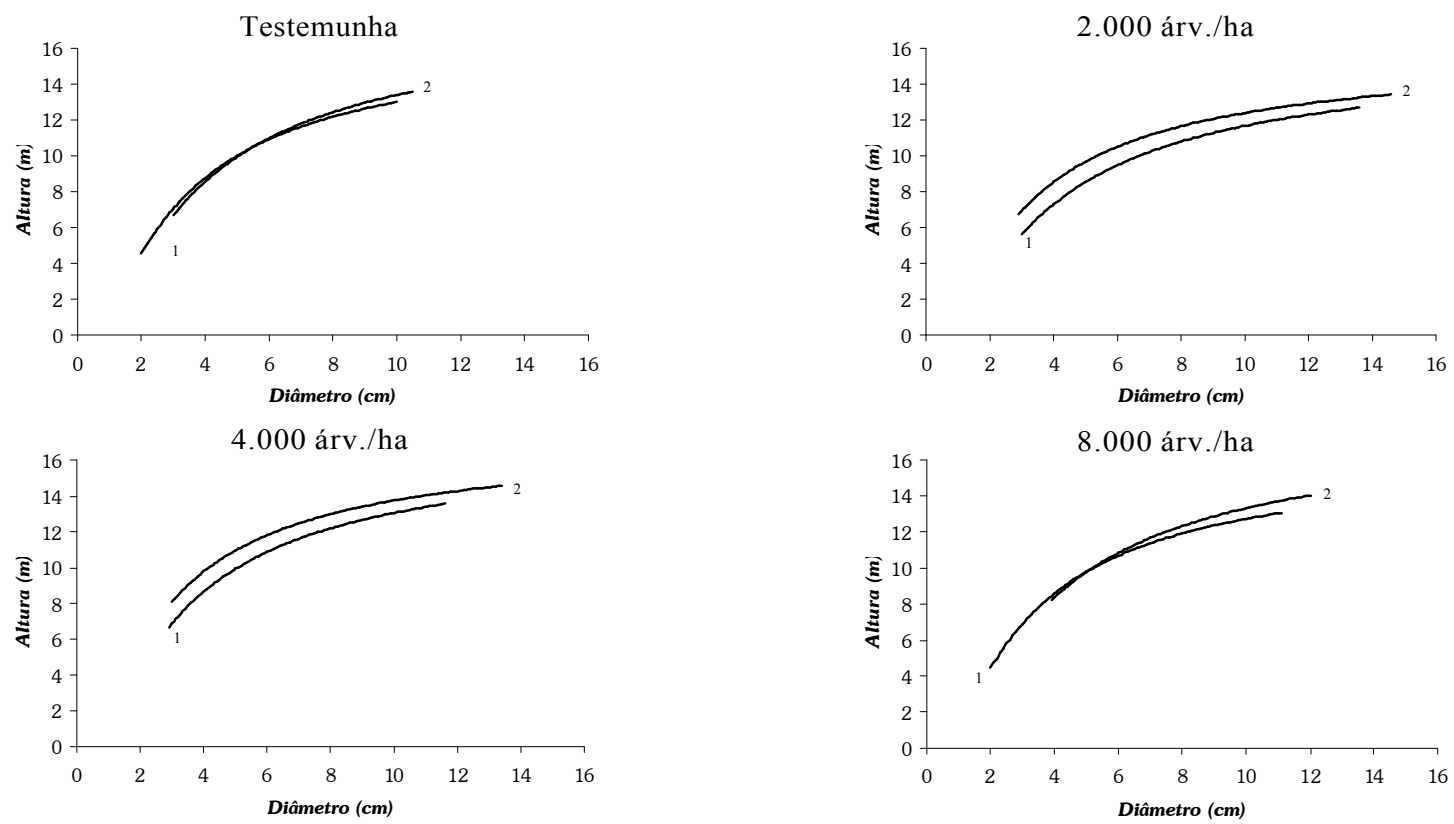

$$
\text { Legenda: (1) } 3,9 \text { anos } \quad \text { (2) } 4,8 \text { anos }
$$

Figura 1 - Curvas de relação hipsométrica das idades de 3,9 e 4,8 anos no sítio I, nos quatro tratamentos de densidade inicial. Figure 1 - Hypsometric relationship curves for the ages 3.9 and 4.8 in site I, for initial density treatments.
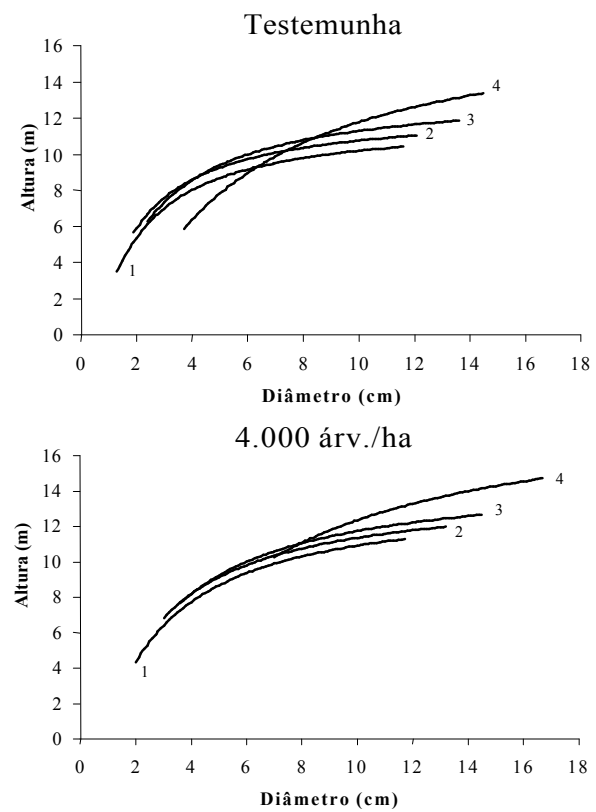

Legenda: (1) 4,1 anos

(2) 5,0 anos

Figura 2 - Curvas de relação hipsométrica das idades de 4,1; 5,0;6,3; e 7,5 anos no sítio II, nos quatro tratamentos de densidade inicial.

Figure 2 - Hypsometric relationship curves for ages 4.1; 5.0; 6.3; and 7.5 years in site II for the 4 treatments of initial density.

R. Árvore, Viçosa-MG, v.28, n.4, p.517-533, 2004 
Quadro 1 - Resultados da análise de co-variância para testar o efeito da idade sobre os dados do sítio I, testemunha e combinação das idades de 3,9 e 4,8 anos

Table 1 - Results of co-variance analysis to test the effect of age on the height-diameter curves for Site I, 3.9 and 4.8 yearolds, and control treatment

\begin{tabular}{|c|c|c|c|c|c|c|c|c|}
\hline & \multicolumn{5}{|c|}{$\begin{array}{c}\text { Soma de quadrados e } \\
\text { produtos corrigidos }\end{array}$} & \multicolumn{2}{|c|}{ Resíduos } & \multirow[t]{2}{*}{$\overline{\text { Teste } F}$} \\
\hline & GL & $\sum y^{2}$ & $\sum x y$ & $\sum x^{2}$ & GL & \multicolumn{2}{|c|}{$\mathrm{SQ}_{\mathrm{res}}$} & \\
\hline 3,9 & 164 & 9,2384 & $-3,2311$ & 1,2313 & 163 & 0,7594 & 0,0047 & - \\
\hline \multirow[t]{3}{*}{4,8} & 76 & 2,4993 & $-0,4351$ & 0,1459 & 75 & 1,2019 & 0,0160 & - \\
\hline & & \multicolumn{3}{|c|}{ resíduos agrupados } & 238 & 1,9613 & 0,0082 & - \\
\hline & & \multicolumn{3}{|c|}{ diferença para testar inclinação } & 1 & 0,0167 & 0,0167 & 2,0291 \\
\hline \multirow[t]{2}{*}{ Total } & 240 & 11,7377 & $-3,6662$ & 1,3772 & 239 & 1,9780 & 0,0083 & - \\
\hline & & \multicolumn{3}{|c|}{ diferença para testar intersecção } & 1 & 0,0002 & 0,0002 & 0,0285 \\
\hline Total & 241 & 13,4622 & $-4,3058$ & 1,6144 & 240 & 1,9782 & 0,0082 & - \\
\hline
\end{tabular}

Legenda: $\mathrm{GL}=$ graus de liberdade, $x=$ variável $1 / d, y=$ variável altura total, $\mathrm{SQ}_{\mathrm{res}}=$ soma dos quadrados dos resíduos e $\mathrm{QM}=$ quadrado médio.

Após resultado significativo de $F$ testando a inclinação, conclui-se que as linhas de regressão não são paralelas. Se as inclinações não são significativamente diferentes, testa-se a diferença em posição, ou seja, dos interceptos. Se estes são diferentes, as regressões também são; caso contrário, as regressões são iguais e podem ser agrupadas (FREESE, 1970).

Analisando o Quadro 2, pode-se comprovar que as diferenças entre as idades são significativas a 5\% nos tratamentos de densidade inicial testemunha e 8.000 árvores/ha quando se avaliou a inclinação e significativas a $1 \%$ nos tratamentos de densidade 2.000 árvores/ha e 4.000 árvores/ha quando se analisou a intersecção. Portanto, o efeito idade não afetou a forma da relação altura/diâmetro nos tratamentos de densidade 2.000 e 4.000 árvores/ha, evidenciando-se uma forma igual das curvas nas idades de 3,9 e 4,8 anos nesses tratamentos. Nos outros tratamentos houve diferença significativa na inclinação. Assim, uma mesma forma dessa relação não pode ser assumida ao longo do tempo nessas idades, comprovando-se a necessidade de ajustar o modelo matemático periodicamente.

Analisando a Figura 2, observa-se que as curvas apresentaram deslocamentos para a direita e para cima com o avanço da idade; ao mesmo tempo foram mais íngremes nas idades iniciais. Ainda ocorreu um cruzamento da curva na idade de 7,5 anos, no tratamento de densidade inicial testemunha.

À exceção das parcelas com sítio II e densidade de 2.000 árvores/ha, que apresentaram ausência de diferença entre idades de 6,3 e 7,5 anos, as outras tiveram diferenças significativas na intersecção (Quadro 3).

Observou-se, em vários casos, que as curvas de altura sobre diâmetro se cruzaram dentro dos limites da amplitude dos dados observados. Curtis (1967), Omule e Mcdonald (1991) citaram a freqüência do cruzamento das linhas de regressão em diferentes idades, mesmo quando provenientes de remedições de parcelas permanentes. Por isso, para evitar esses cruzamentos, Curtis (1967) propôs a inclusão da idade como variável independente no modelo de regressão. $\mathrm{Na}$ Figura 3, observam-se tais cruzamentos em todos os tratamentos na idade de 7,6 anos e, também, os deslocamentos das curvas para cima e para a direita.

Quadro 2 - Valores do teste $F$ encontrados na análise de co-variância envolvendo a combinação das idades de 3,9 e 4,8 anos, no sítio I e nos quatro tratamentos de densidade inicial, na avaliação do fator idade

Table 2 - F values from analysis of covariance involving combination of 3.9 and 4.8 year-olds in site I and in the 4 initial density treatments for evaluation of age effect

\begin{tabular}{lcccc}
\hline \multicolumn{4}{c}{ Tratamentos } \\
& Testemunha & \multicolumn{1}{c}{2.000} & \multicolumn{1}{c}{4.000} & 8.000 \\
\hline Inclinação & $2,0291^{*}$ & $2,6960^{\mathrm{ns}}$ & $2,5378^{\mathrm{ns}}$ & $4,1410^{*}$ \\
Intersecção & $0,0285^{\mathrm{ns}}$ & $12,4593^{* *}$ & $19,9248^{* *}$ & $4,2058^{*}$ \\
\hline
\end{tabular}

Legenda: ns - não-significativo; * - significativo a 5\%; ** - significativo a $1 \%$. 
Quadro 3 - Valores do teste $F$ encontrados na análise de co-variância envolvendo a combinação das quatro idades de medição no sítio II e nos quatro tratamentos de densidade inicial, na avaliação do fator idade

Table 3 - F values from the analysis of covariance involving combinations of 4 measurement ages in site II and in the 4 initial density treatments for evaluation of age effects

\begin{tabular}{|c|c|c|c|c|c|c|}
\hline & \multicolumn{6}{|c|}{ Idades (anos) } \\
\hline & $4,1-5,0$ & $4,1-6,3$ & $4,1-7,5$ & $5,0-6,3$ & $5,0-7,5$ & $6,3-7,5$ \\
\hline & \multicolumn{6}{|c|}{ Densidade Testemunha } \\
\hline Inclinação & $1,0695^{\mathrm{ns}}$ & $4,7206^{*}$ & $76,7974^{* *}$ & $5,6471^{*}$ & $58,1943^{* *}$ & $52,5994^{* *}$ \\
\hline \multirow[t]{2}{*}{ Intersecção } & $56,2415^{* *}$ & $113,6493^{* *}$ & $14,1074^{* *}$ & $9,5926^{* *}$ & $0,0456^{\mathrm{ns}}$ & $6,1694^{*}$ \\
\hline & \multicolumn{6}{|c|}{ Densidade 2.000 árv./ha } \\
\hline Inclinação & $0,4734^{\mathrm{ns}}$ & $2,0083^{\mathrm{ns}}$ & $0,2799^{\mathrm{ns}}$ & $0,6426^{\text {ns }}$ & $0,0862^{\mathrm{ns}}$ & $0,0053^{\mathrm{ns}}$ \\
\hline \multirow[t]{2}{*}{ Intersecção } & $34,0630^{* *}$ & $74,4599^{* *}$ & $48,9019^{* *}$ & $9,9506^{* *}$ & $13,2701^{* *}$ & $2,2755^{\mathrm{ns}}$ \\
\hline & \multicolumn{6}{|c|}{ Densidade 4.000 árv./ha } \\
\hline Inclinação & $0,5162^{\mathrm{ns}}$ & $0,2682^{\mathrm{ns}}$ & $10,5121^{* *}$ & $1,3268^{\mathrm{ns}}$ & $16,1299^{* *}$ & $10,0754^{* *}$ \\
\hline \multirow{2}{*}{ Intersecção } & $29,9486^{* *}$ & $51,3141^{* *}$ & $64,3433^{* *}$ & $10,3622^{* *}$ & $35,3933^{* *}$ & $11,7225^{* *}$ \\
\hline & \multicolumn{6}{|c|}{ Densidade 8.000 árv./ha } \\
\hline Inclinação & $2,2903^{\mathrm{ns}}$ & $0,1453^{\mathrm{ns}}$ & $8,1573^{* *}$ & $2,5095^{\mathrm{ns}}$ & $14,3582^{* *}$ & $8,4710^{* *}$ \\
\hline Intersecção & $17,1879^{* *}$ & $80,1995^{* *}$ & $91,0865^{* *}$ & $42,9121^{* *}$ & $71,2847^{* *}$ & $14,7923^{* *}$ \\
\hline
\end{tabular}

Legenda: $\mathrm{ns}=$ não-significativo, $*=$ significativo a $5 \%$ e $* *=$ significativo a $1 \%$.

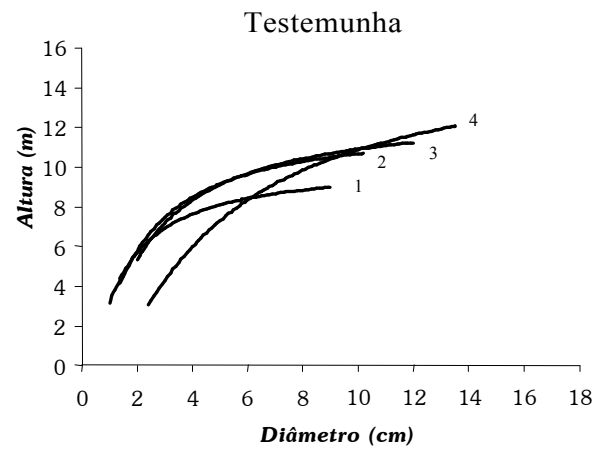

4.000 árv./ha

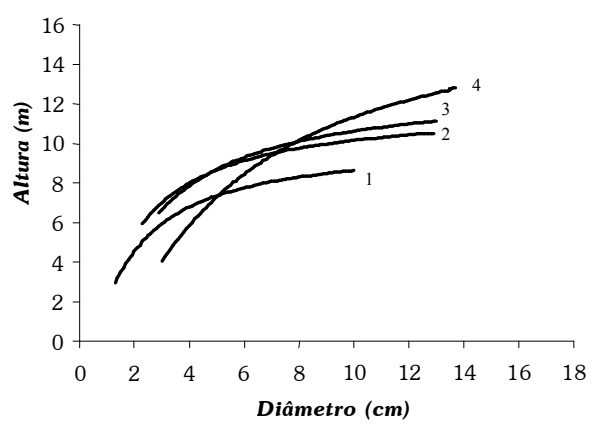

Legenda: (1) 4,2 anos

(2) 5,4 anos

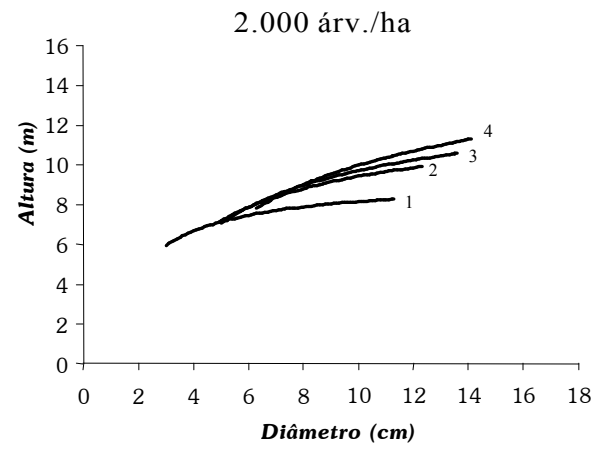

8.000 árv./ha

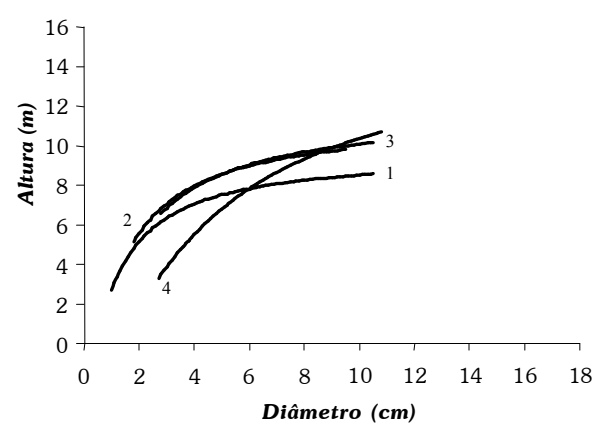

(3) 6,3 anos (4) 7,6 anos

Figura 3 - Curvas de relação hipsométrica, sítio III, idades de 4,2; 5,4; 6,3; e 7,6 anos, nos quatro tratamentos de densidade inicial.

Figure 3 - Hypsometric relationship curves of site class III, 4.2; 5.4; 6.3; and 7.3 year-olds for the 4 initial density treatments. 
No tratamento 2.000 árvores/ha do sítio III, verificou-se ausência de diferença entre as idades de $5,4 \operatorname{com} 6,3$ anos e 6,3 com 7,6 anos, e no tratamento 8.000 árvores/ha não diferiram as idades de 5,4 com 6,3 anos. Essa ausência de diferença, que também havia sido observada no sítio II, provavelmente ocorreu por interferência do fator tratamento. Nos tratamentostestemunha e 4.000 árvores/ha foram verificadas diferenças significativas, comprovando que há influência da idade na relação hipsométrica. Por isso, devemse refazer, anualmente, as curvas hipsométricas, principalmente na fase jovem do povoamento, quando ocorre o maior incremento em altura (Quadro 4).

Machado et al. (1994) obtiveram resultados similares em relação aos efeitos dos fatores sítio, idade e densidade, apesar de terem utilizado outro modelo para o ajuste e outro teste para a comparação das curvas. Trabalharam com Pinus elliottii no Estado do Paraná e utilizaram o modelo de Henricksen para o traçado gráfico das linhas de regressão altura/diâmetro em vários grupos de idade. Dessas linhas de regressão foram obtidos valores médios de alturas estimadas para a comparação de médias entre os grupos de idade sobre a relação hipsométrica. Foram comparados apenas os grupos de idade com pelo menos quatro médias se sobrepondo, e os testes de comparação de médias não detectaram diferença significativa entre quase todos os grupos consecutivos de idade. No entanto, as diferenças ocorreram entre as idades de 13-14 e 21-
23 anos, em que há maior diferença de idade. Com os grupos de idade de 21-23 e 28-29 anos, também não houve diferença, nesse caso por haver estabilização da relação hipsométrica com o avanço da idade.

Azevedo et al. (1999), com base no teste de identidade de modelos que faz a comparação das linhas de regressão através dos seus coeficientes, concluíram que a relação altura/diâmetro varia de acordo com a idade do povoamento, não podendo ser utilizada uma equação comum em todas as quatro diferentes idades para cada uma das quatro espécies estudadas (andiroba, sumaúma, ucuúba e ipê-rosa) em plantio homogêneo situado na Amazônia ocidental. Portanto, os resultados do presente trabalho vêm corroborar os citados na pesquisa desses autores, em que a idade afeta a relação hipsométrica.

\subsection{Análise do fator sítio na relação hipsométrica}

O comportamento das curvas de relação hipsométrica em relação ao fator sítio foi similar ao das curvas em relação ao fator idade, ou seja, em locais mais produtivos (índice de sítio de $16,8 \mathrm{~m}$ ) a inclinação da curva foi ligeiramente mais acentuada do que nos locais menos produtivos (índice de sítio de 10,2 m). As propriedades que representam o sítio I não continham parcelas com as idades de 6,3 e 7,6 anos (medições 5 e 6), portanto algumas curvas foram traçadas somente nos sítios I e II.

Quadro 4 - Valores do teste $F$ encontrados na análise de co-variância envolvendo a combinação das quatro idades de medição no sítio III e nos quatro tratamentos de densidade inicial, na avaliação do fator idade

Table 4 - F values from the analysis of covariance to test the effects of the 4 measurement ages on site III and the 4 initial density treatments

\begin{tabular}{|c|c|c|c|c|c|c|}
\hline \multicolumn{7}{|c|}{ Idades (anos) } \\
\hline & $4,2-5,4$ & $4,2-6,3$ & $4,1-7,5$ & $5,4-6,3$ & $5,0-7,6$ & $6,3-7,6$ \\
\hline \multicolumn{7}{|c|}{ Densidade Testemunha } \\
\hline Inclinação & $41,3367^{* *}$ & $54,5643^{* *}$ & $249,4576^{* *}$ & $13,0228^{* *}$ & $195,2928^{* *}$ & $125,6935^{* *}$ \\
\hline Intersecção & $297,0825^{* *}$ & $292,1558^{* *}$ & $0,1803^{\mathrm{ns}}$ & $0,5974^{\mathrm{ns}}$ & $143,1565^{* *}$ & $154,5144^{* *}$ \\
\hline \multicolumn{7}{|c|}{ Densidade 2.000 árv./ha } \\
\hline Inclinação & $10,0981^{* *}$ & $14,5123^{* *}$ & $13,1564^{* *}$ & $0,7744^{\mathrm{ns}}$ & $3,5461^{*}$ & $1,5645^{\mathrm{ns}}$ \\
\hline Intersecção & $62,5832^{* *}$ & $94,7515^{* *}$ & $115,5853^{* *}$ & $3,2046^{\mathrm{ns}}$ & $10,2284^{* *}$ & $2,7116^{\mathrm{ns}}$ \\
\hline \multicolumn{7}{|c|}{ Densidade 4.000 árv./ha } \\
\hline Inclinação & $0,0115^{\mathrm{ns}}$ & $4,5106^{*}$ & $93,8701^{* *}$ & $6,2986^{*}$ & $132,1223^{* *}$ & $99,9778^{* *}$ \\
\hline Intersecção & $213,8142^{* *}$ & $280,5491^{* *}$ & $145,2220^{* *}$ & $10,0758^{* *}$ & $4,1817^{*}$ & $0,0022^{\mathrm{ns}}$ \\
\hline \multicolumn{7}{|c|}{ Densidade 8.000 árv./ha } \\
\hline Inclinação & $3,4449^{\text {ns }}$ & $7,3593^{* *}$ & $159,5630^{* *}$ & $3,3668^{\mathrm{ns}}$ & $193,0725^{* *}$ & $124,3523^{* *}$ \\
\hline Intersecção & $283,0912^{* *}$ & $257,4763^{* *}$ & $0,6575^{\text {ns }}$ & $0,0673^{\mathrm{ns}}$ & $136,1475^{* *}$ & $148,9777^{* *}$ \\
\hline
\end{tabular}

Legenda: ns= não-significativo, $*=$ significativo a $5 \% \mathrm{e}^{* *}=$ significativo a $1 \%$. 
A análise gráfica dos resíduos comprovou esse efeito, ficando as distribuições mais homogêneas com o sítio mais produtivo (sítio I). Os melhores ajustes apareceram nas análises das combinações com o sítio I.

O comportamento de deslocamento para cima e para a direita das curvas dos sítios menos produtivos para os mais produtivos pode ser verificado nas Figuras 4 a 7. O cruzamento das curvas de altura/diâmetro em alguns tratamentos refletiu a diferente natureza dos dados, pois pertenciam a sítios diferentes (Figura 4). Portanto, para evitar esses cruzamentos, sugere-se a proposta de Curtis (1967) ou a metodologia de ajuste simultâneo de curvas altura/diâmetro referentes a diferentes idades de uma parcela remedida, desenvolvida por Omule e Mcdonald (1991).

Pela visualização gráfica das curvas das Figuras 4 a 7 , evidencia-se que há uma grande diferença entre os vários sítios, pois elas se encontravam relativamente distanciadas na maioria dos casos. A análise de co-variância que consta do Quadro 5 indica os valores do teste $F$ das várias combinações de sítio, nas diversas idades de medição e densidades iniciais.

Constatam-se, no Quadro 5, diferenças significativas tanto na inclinação quanto na intersecção das medições 3, 4, 5 e 6; e somente na intersecção das medições 5 e 6 correspondente às idades: de 3,9; 4,1; e 4,2 anos (medição 3); 5,0; e 5,4 anos (medição 4); 6,3 anos (medição 5); e 7,5; e 7,6 anos (medição 6), nas combinações dos três sítios. Na testemunha, na medição 4 não houve diferença entre os sítios II e III, ou seja, esses dados podem ser agrupados; logo, os sítios II e III tiveram o mesmo efeito na relação, portanto a relação hipsométrica não foi afetada nas idades de 5 e 5,4 anos nesses sítios e na densidade inicial testemunha. Nas outras densidades, as diferenças entre os sítios foram significativas.

O sítio, expressando toda a capacidade produtiva de um terreno florestal, exerce influência sobre a curva de relação hipsométrica. Resultados similares foram encontrados por Cardoso (1989), que, analisando o fator sítio, verificou que houve efeito significativo somente sobre o coeficiente de intersecção e não na inclinação das linhas de regressão, dentro da maioria das classes de idade de plantações de Pinus taeda no Paraná. Nas idades em que a diferença entre inclina- ções foi considerada significativa (5-6, 7-8, 14 e 20 anos), verificou-se a situação nítida de que em sítios bons a linha foi mais íngreme, se comparada com a linha em sítios ruins, além de uma tendência crescente das linhas do pior para o melhor sítio em cada classe de idade. Essa mesma evolução foi encontrada por Schimdt (1977) nas linhas de regressão, dentro da maioria das classes de idade de plantações de Pinus taeda na região de Guarapuava, Paraná.

Machado et al. (1993), trabalhando com Pinus elliottii no Paraná, testaram modelos de relação hipsométrica em diferentes sítios e idades e, com o modelo de Henricksen, traçaram as linhas de regressão por classe de sítio de cada idade. Concluíram que o sítio exerceu efeito moderado sobre a relação hipsométrica, sendo significativo apenas entre classes de sítio mais afastadas, fato que diverge do relatado no trabalho em questão, o qual evidenciou que o sítio exerceu influência na relação hipsométrica entre todas as classes.

O mesmo resultado, encontrado em algumas combinações de sítio do presente trabalho, foi obtido por Buford (1986) em Pinus taeda aos 15 anos de idade, em que as inclinações da curva altura/diâmetro ajustada, com o mesmo modelo escolhido para este trabalho, foram as mesmas em todas as procedências de semente em oito dos nove locais de estudo no sul dos Estados Unidos. Os interceptos das relações hipsométricas foram diferentes com relação às procedências em seis dos nove locais. Portanto, o resultado indicou que houve uma forma da curva igual em todas as procedências, mas ocorreu um deslocamento das curvas relativas a cada sítio estudado. O nível da curva foi fortemente relacionado à altura dominante na idade de 15 anos.

Hammer (1981) encontrou diferenças significativas entre curvas hipsométricas elaboradas para pinus cipreste (Callitris columellaris F. Muell) em Maningrida e Murganella (Austrália), em comparação com curvas elaboradas para a mesma espécie em outro local (Queensland/Austrália). O mesmo foi verificado por Nowak (1990) quando ajustou curvas hipsométricas para Acer platanoides, A. saccharum e A. saccharinum, em diferentes locais (Rochester e Syracuse) de Nova York-EUA, evidenciando a influência do fator sítio na relação diâmetro/altura.

R. Árvore, Viçosa-MG, v.28, n.4, p.517-533, 2004 

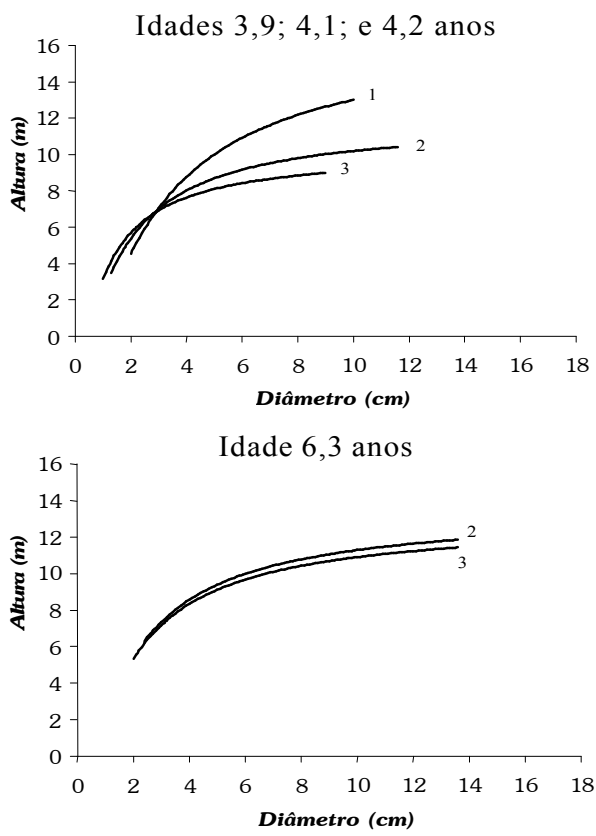

Legenda: (1) sítio I
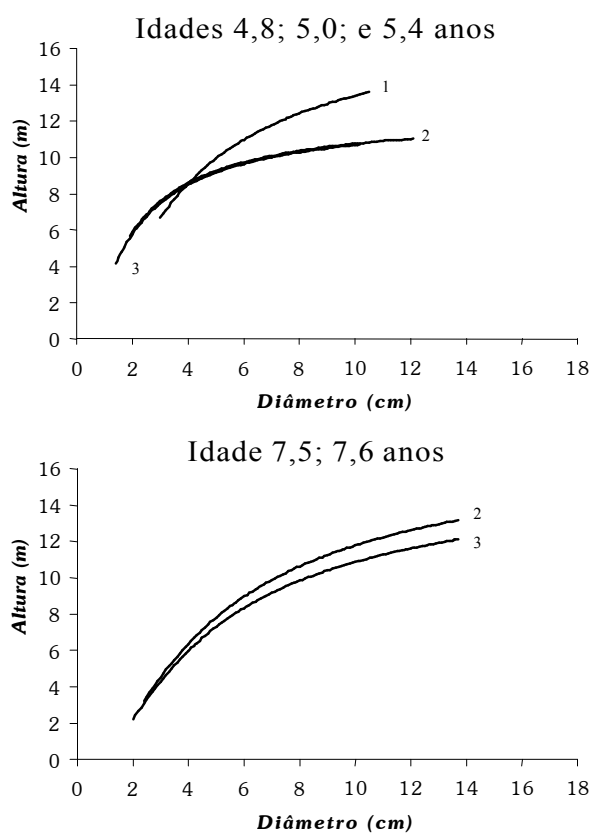

(3) sítio III

Figura 4 - Curvas hipsométricas dos sítios I, II e III, nas várias idades de medição e densidade inicial testemunha.

Figure 4 - Heigth-diameter relationship on sites I, II, and III for all measurement ages and for the control treatment.
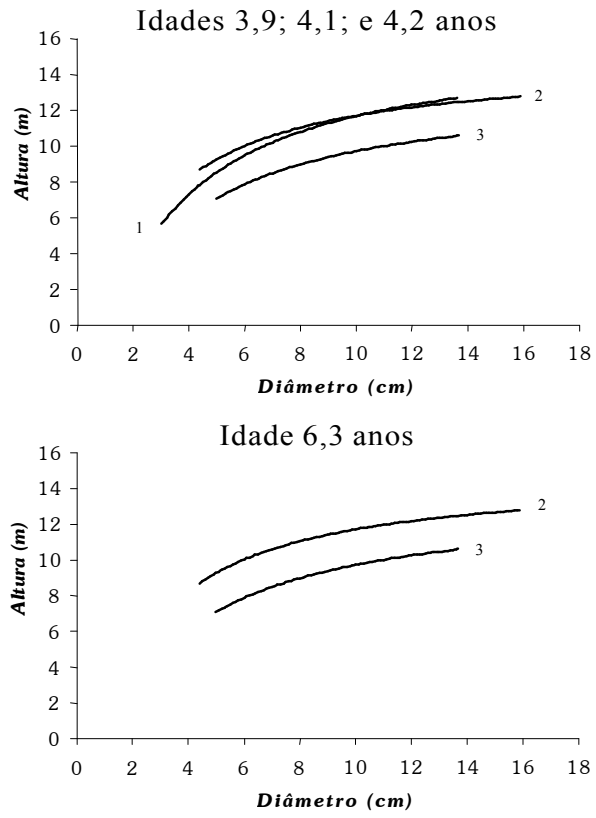

Legenda: (1) sítio I
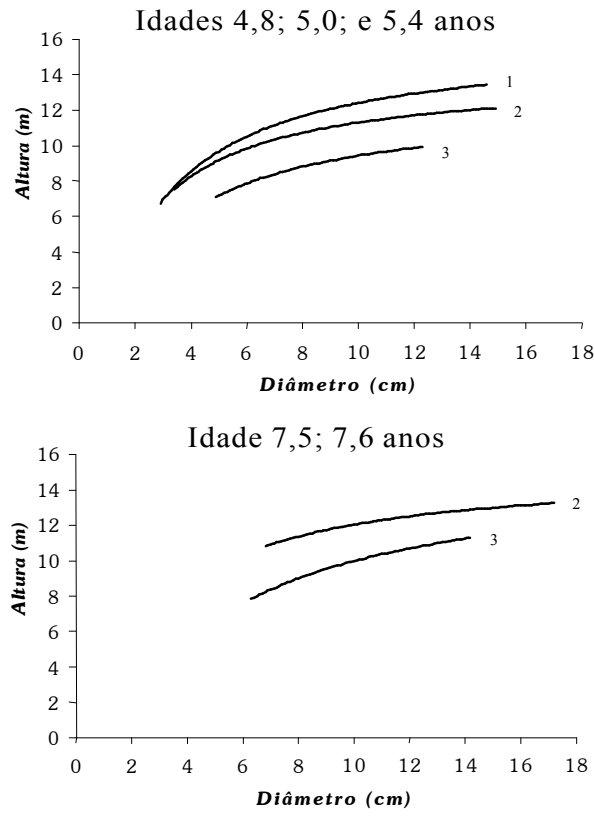

(2) sítio II

Figura 5 - Curvas hipsométricas dos sítios I, II e III, nas várias idades de medição e densidade inicial de 2.000 árv./ha. Figure 5 - Height-diameter curves in sites I, II, and III, for all measurement ages and initial density of 2,000 trees per hectare.

R. Árvore, Viçosa-MG, v.28, n.4, p.517-533, 2004 
Dinâmica da relação hipsométrica em função da idade, ...
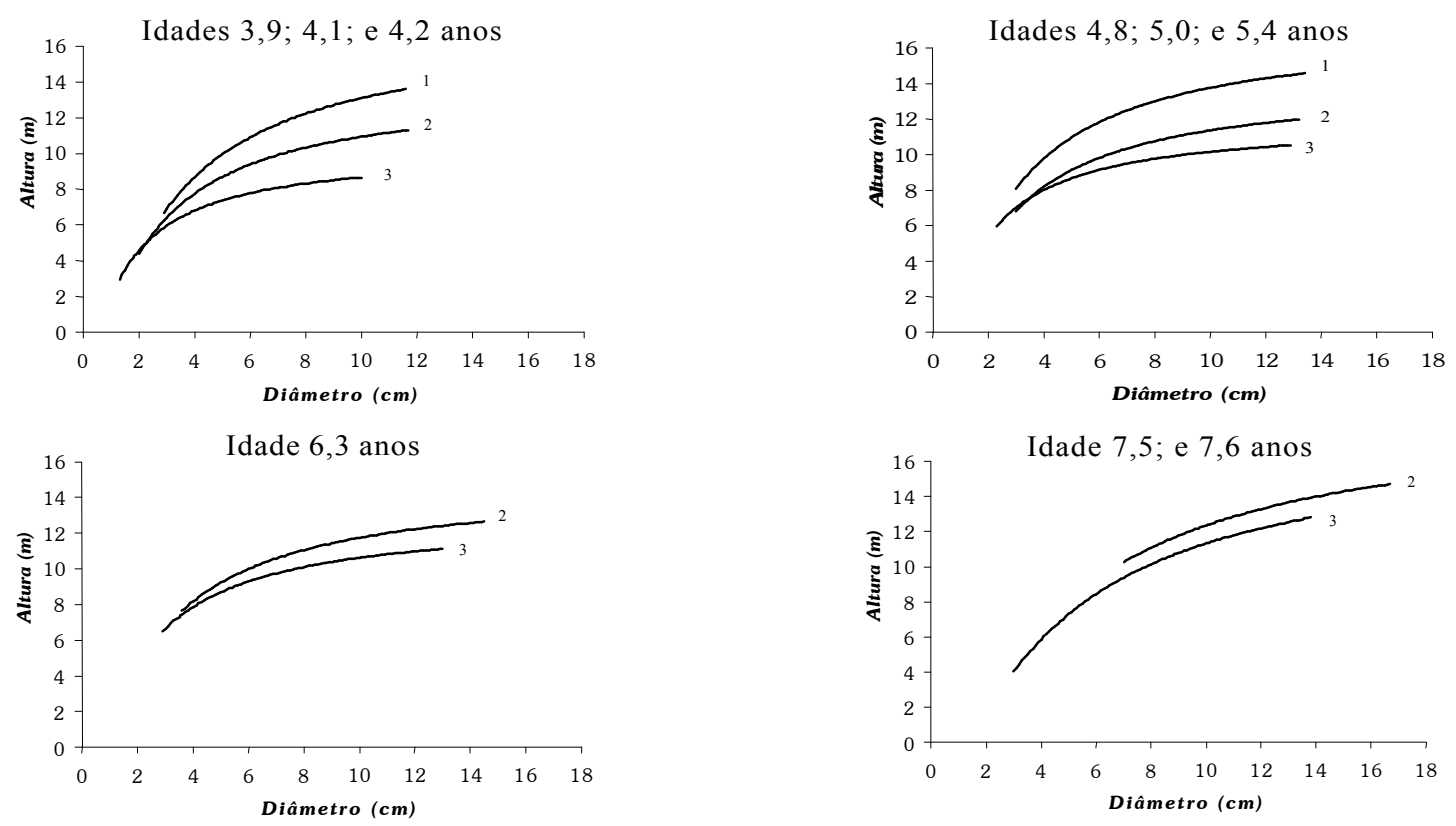
Legenda:
(1) sítio I
(2) sítio II
(3) sítio III

Figura 6 - Curvas hipsométricas dos sítios I, II e III, nas várias idades de medição e densidade inicial de 4.000 árv./ha. Figure 6 - Height-diameter curves in sites I, II, and III for all measurement ages and initial density of 4,000 trees per hectare.
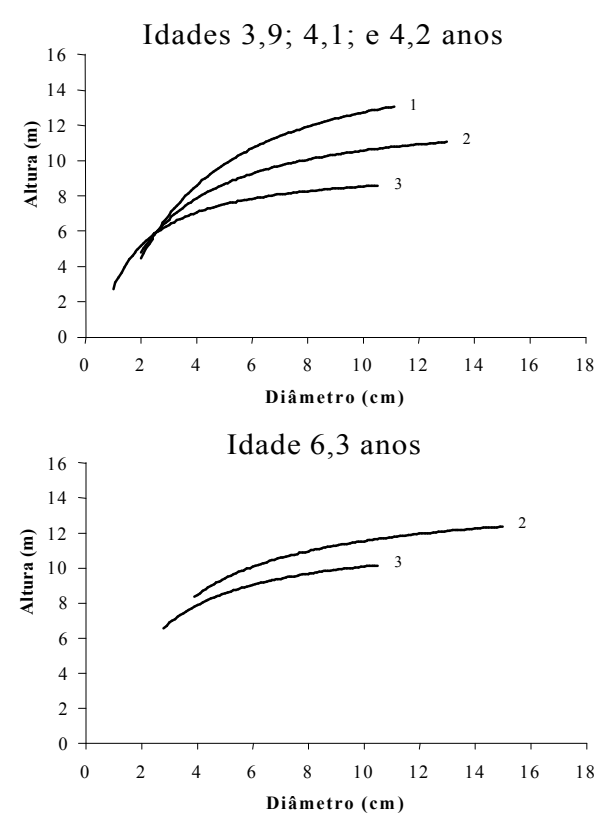

Legenda: (1) sítio I
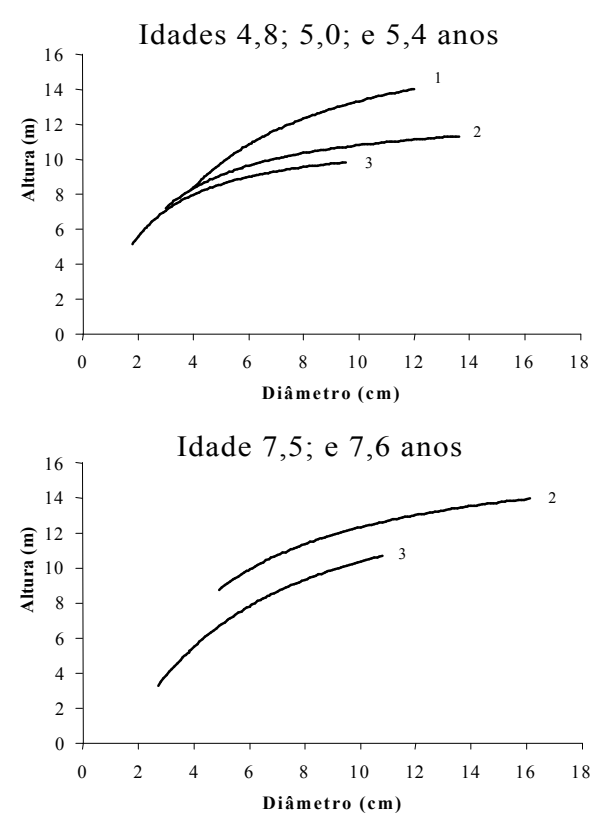

(2) sítio II

(3) sítio III

Figura 7 - Curvas hipsométricas dos sítios I, II e III, nas várias idades de medição e densidade inicial de 8.000 árv./ha. Figure 7 - Height-diameter curves in sites I, II, and III for all measurement ages and initial density with 8,000 trees per hectare. 
Quadro 5 - Valores do teste $F$ da análise de co-variância envolvendo a combinação dos três sítios nas várias idades de medição e os quatro tratamentos de densidade inicial, na avaliação do efeito do fator sítio

Table $5-F$ values from analysis of covariance involving combinations of 3 sites, several measurement ages and 4 initial density treatments to evaluate site effects

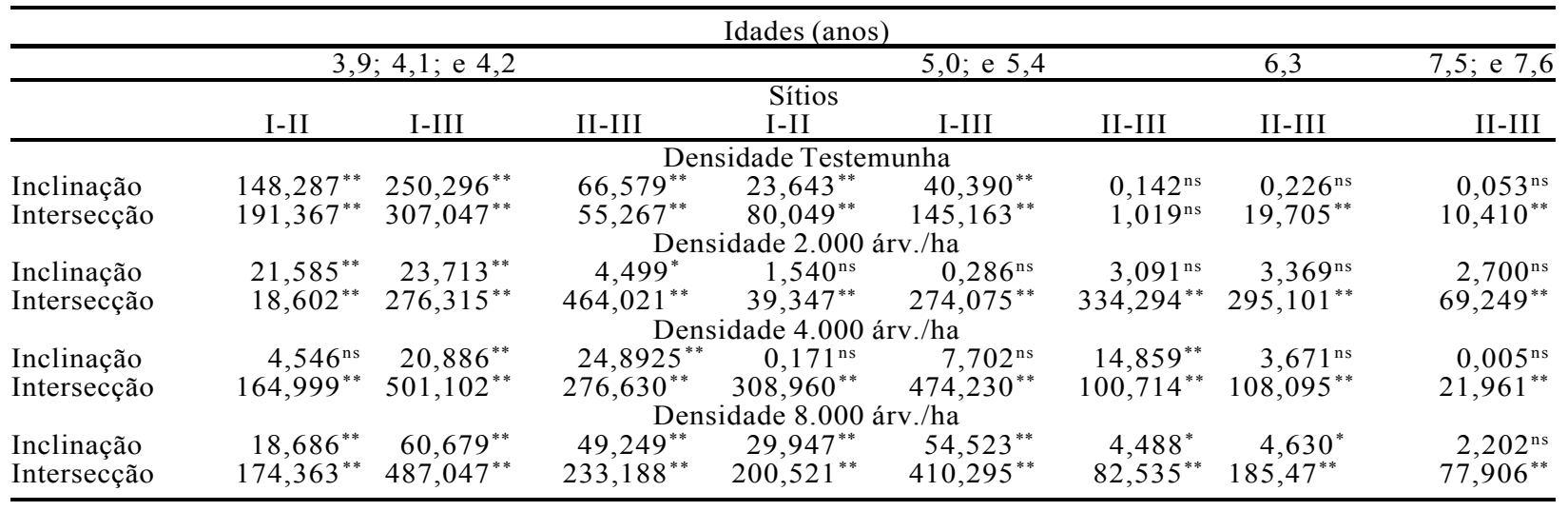

Legenda: medição 3 (3,9; 4,1; e 4,2 anos), medição 4 (5,0 ; e 5,4 anos), medição 5 (6,3 anos) e medição 6 (7,5; e 7,6 anos), ns $=$ não-significativo, $*=$ significativo a $5 \%$ e $* *=$ significativo a $1 \%$.

\subsection{Análise do fator densidade na relação hipsométrica}

As curvas de relação hipsométrica foram mais íngremes nas densidades maiores, visto que a concorrência (densidade) afeta mais o crescimento em diâmetro do que em altura e, em conseqüência, a relação hipsométrica.

Nas árvores dominantes, a altura é pouco afetada pelo espaçamento, já nas dominadas a influência desse efeito é acentuada. No entanto, o diâmetro é bastante afetado pela concorrência em qualquer estrato da floresta. Assim, quando a concorrência é alta, a razão $h / d$ é maior. Povoamentos muito densos ten- dem, naturalmente, a apresentar árvores de diâmetros menores em comparação com árvores de povoamentos pouco densos, em que a concorrência por espaço é menor e o crescimento em diâmetro, mais acentuado.

Esse efeito é ilustrado na Figura 8, em que as curvas se movem para cima das menores nas maiores densidades. Porém não é muito pronunciado nas densidades-testemunha e 8.000 árvores/ha, as quais estão muito próximas, indicando um paralelismo entre as respectivas curvas. Através da análise de co-variância, pode-se constatar essa hipótese (Quadro 6).
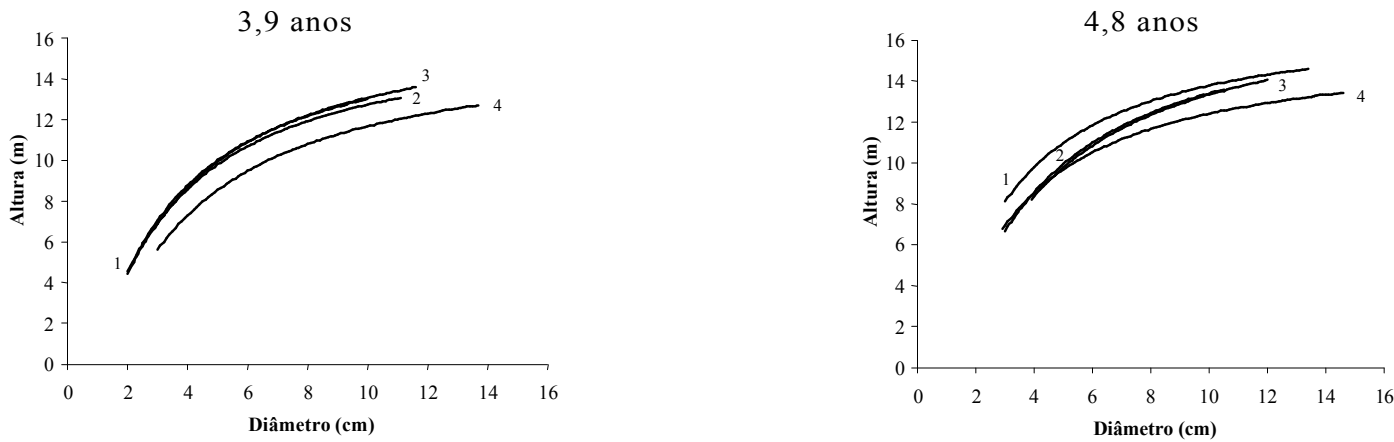

Legenda: (1) Testemunha, (2) 8.000, (3) 4.000, (4) 2.000 árvores/ha

Figura 8 - Curvas hipsométricas do sítio I, nas idades de 3,9 e 4,8 anos, nos quatro tratamentos de densidade inicial. Figure 8 -Height-diameter curves for site I, 3.9 and 4.8 year-olds, for the 4 initial density treatments. 
Quadro 6 - Valores do teste $F$ na análise de co-variância, envolvendo a combinação dos quatro tratamentos de densidade inicial do sítio I, nas idades de 3,9 e 4,8 anos, na avaliação do efeito do fator densidade

Table $6-F$ values from analysis of covariance involving combinations of 4 initial density treatments for site I, 3.9 and 4.8 year-olds to evaluate density effects

\begin{tabular}{lcccrrr}
\hline & \multicolumn{7}{c}{ Densidade inicial (número de árvores/ha) } \\
\hline & Test-2.000 & Test-4.000 & Test-8.000 & $2.000-4.000$ & $2.000-8.000$ & $4.000-8.000$ \\
\hline Inclinação & $5,5620^{*}$ & $0,5059^{\mathrm{ns}}$ & $0,00003^{\mathrm{ns}}$ & $1,5340^{\mathrm{ns}}$ & $4,3467^{*}$ & $0,3665^{\mathrm{ns}}$ \\
Intersecção & $81,2767^{* *}$ & $0,0814^{* *}$ & $5,5423^{\mathrm{ns}}$ & $54,5685^{* *}$ & $50,5307^{* *}$ & $2,3456^{*}$ \\
& & 4,8 anos & & & \\
Inclinação & $1,0154^{\mathrm{ns}}$ & $3,0310^{\mathrm{ns}}$ & $0,0831^{\mathrm{ns}}$ & $0,2911^{\mathrm{ns}}$ & $3,0400^{\mathrm{ns}}$ & $6,6993^{\mathrm{ns}}$ \\
Intersecção & $6,0047^{*}$ & $9,7561^{* *}$ & $0,0764^{\mathrm{ns}}$ & $34,6289^{* *}$ & $13,3699^{* *}$ & $17,6127^{* *}$ \\
\hline
\end{tabular}

Legenda: ns= não-significativo, $*=$ significativo a $5 \%$ e $* *=$ significativo a $1 \%$, Test - testemunha.

Através dos testes de paralelismo e coincidência, comprovou-se o que foi visualizado na Figura 8, ou seja, as curvas geradas pelas parcelas localizadas no sítio I e com idades de 3,9 e 4,8 anos apresentaram ausência de diferença entre os tratamentos-testemunha e 8.000 árvores/ha; as outras exibiram diferenças significativas na intersecção. Certamente isso ocorreu porque o tratamento de 8.000 árvores/ha
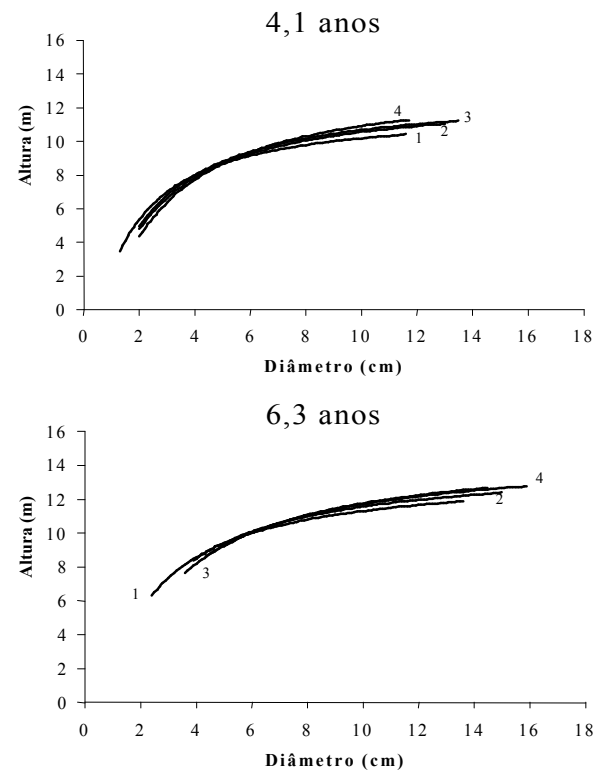

Legenda: (1) Testemunha, (2) 8.000, apresentou densidade relativamente mais próxima à da testemunha.

Nas outras idades de medição do sítio II também foi verificado esse efeito entre as linhas de regressão nos tratamentos-testemunha e 8.000 árvores/ha, em que ocorreu a sobreposição dessas linhas (Figura 9). Pelo teste $F$ da análise de co-variância, comprovou-se, novamente, tal efeito (Quadro 7).
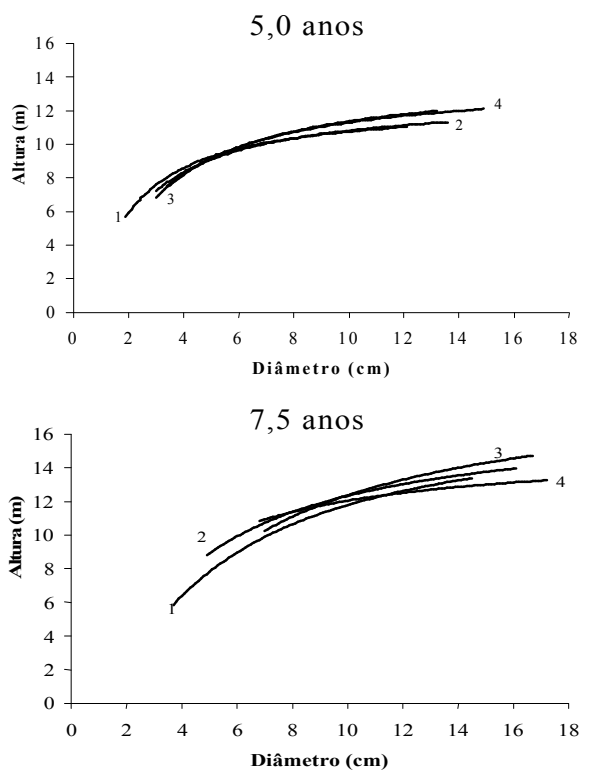

(3) $4.000, \quad$ (4) 2.000 árvores/ha

Figura 9 - Curvas hipsométricas do sítio II, nas idades de 4,1 a 7,5 anos, nos quatro tratamentos de densidade inicial. Figure 9 - Height-diameter curves, on site II, from 4.1 to 7.5 year-olds for the 4 initial density treatments. 
Quadro 7 - Valores do teste $F$ da análise de co-variância, envolvendo a combinação dos quatro tratamentos de densidade inicial do sítio II, nas idades de 4,1 a 7,5 anos, na avaliação do efeito do fator densidade

Table $7-F$ values from analysis of covariance involving combinations of 4 treatments, from 4.1 to 7.5 year-olds, on site II, to evaluate density effect

\begin{tabular}{|c|c|c|c|c|c|c|}
\hline \multicolumn{7}{|c|}{ Densidade inicial (número de árvores/ha) } \\
\hline & Test-2.000 & Test-4.000 & Test- 8.000 & $2.000-4.000$ & $2.000-8.000$ & $4.000-8.000$ \\
\hline & & & 4,1 anos & & & \\
\hline Inclinação & $3,3678^{\text {ns }}$ & $48,3697^{* *}$ & $19,6456^{* *}$ & $3,7249^{\mathrm{ns}}$ & $0,0770^{\mathrm{ns}}$ & $6,9705^{* *}$ \\
\hline Intersecção & $14,7808^{* *}$ & $4,2704^{* *}$ & $\begin{array}{l}0,0001 \mathrm{~ns} \\
5,0 \text { anos }\end{array}$ & $0,4416^{\mathrm{ns}}$ & $2,0418^{\mathrm{ns}}$ & $1,3813 \mathrm{~ns}$ \\
\hline Inclinação & $4,4414^{\mathrm{ns}}$ & $16,8159^{* *}$ & $1,7626^{\mathrm{ns}}$ & $0,2207^{\mathrm{ns}}$ & $2,2264^{\mathrm{ns}}$ & $7,8324^{* *}$ \\
\hline Intersecção & $9,0487^{* *}$ & $5,8536^{*}$ & $\begin{array}{l}0,2145^{\mathrm{ns}} \\
6,3 \text { anos }\end{array}$ & $0,1905^{\mathrm{ns}}$ & $14,6028^{* *}$ & $16,4658^{* *}$ \\
\hline Inclinação & $2,8043^{\mathrm{ns}}$ & $7,2296^{* *}$ & $1,1852^{\mathrm{ns}}$ & $0,0465^{\mathrm{ns}}$ & $0,8893^{\mathrm{ns}}$ & $2,2915^{\mathrm{ns}}$ \\
\hline Intersecção & $7,3136^{* *}$ & $7,0472^{* *}$ & $\begin{array}{l}3,3665 \text { ns } \\
7,5 \text { anos }\end{array}$ & $0,1380^{\mathrm{ns}}$ & $0,6264^{\mathrm{ns}}$ & 0,8922 ns \\
\hline Inclinação & $2,4132 \mathrm{~ns}$ & $0,0738^{\mathrm{ns}}$ & $1,5806^{\mathrm{ns}}$ & $2,7529 \mathrm{~ns}$ & $0,9993^{\mathrm{ns}}$ & $1,5841^{\mathrm{ns}}$ \\
\hline Intersecção & $0,8291 \mathrm{~ns}$ & $3,4707^{\mathrm{ns}}$ & $7,5893^{* *}$ & $1,4994 \mathrm{~ns}$ & $1,2252 \mathrm{~ns}$ & $0,0027^{\mathrm{ns}}$ \\
\hline
\end{tabular}

Legenda: $\mathrm{ns}=$ não-significativo, $*=$ significativo a $5 \%, * *=$ significativo a $1 \%$ e Test $=$ testemunha

A mesma ausência de diferença significativa encontrada no sítio I ocorreu nas parcelas do sítio II, na idade de 4,1 anos, nas densidade de $2.000 \mathrm{com}$ a de 4.000 árvores/ha e 2.000 com a de 8.000 árvores/ ha. $\mathrm{Na}$ idade de 5,0 anos, as diferenças não foram significativas entre as densidades-testemunha de 8.000 e 2.000 com a de 4.000 árvores/ha. Na idade de 6,3 anos, além dessas combinações de densidades, as densidades de 4.000 com a de 8.000 não apresentaram diferenças significativas. Na idade de 7,5 anos, a única combinação que apresentou diferença significativa foi a do tratamento-testemunha com 8.000 árvores/ha. As outras combinações de densidade apresentaram paralelismo entre as linhas, podendo-se concluir que o fator densidade praticamente não afetou a relação hipsométrica desse sítio nessas idades.

Já no sítio III e na idade de 5,4 anos os tratamentos de 4.000 com o de 8.000 árvores/ha e na idade de 7,6 dos tratamentos 2.000 com 8.000 árvores/ha apresentaram ausência de significância. Nas outras idades de medição houve diferença significativa entre as curvas dos tratamentos. Os valores da análise de co-variância nesse sítio são apresentados no Quadro 8.

Quadro 8 - Valores do teste $F$ na análise de co-variância envolvendo a combinação dos quatro tratamentos de densidade inicial do sítio III e nas idades de 4,2 a 7,6 anos, na avaliação do efeito do fator densidade

Table 8 - F values from analysis of covariance involving combinations of 4 treatments for site III, from 4.1 to 7.5 yearolds, evaluating density effects

\begin{tabular}{|c|c|c|c|c|c|c|}
\hline \multicolumn{7}{|c|}{ Densidade inicial (número de árvores/ha) } \\
\hline & Test-2.000 & Test-4.000 & Test- 8.000 & $2.000-4.000$ & $2.000-8.000$ & $4.000-8.000$ \\
\hline & & & 4,2 anos & & & \\
\hline Inclinação & $0,4104^{\mathrm{ns}}$ & $21,7325^{* *}$ & 1,9752 ns & $0,8359^{\mathrm{ns}}$ & $0,0776^{\text {ns }}$ & $9,5841^{* *}$ \\
\hline Intersecção & $93,6156^{* *}$ & $98,7258^{* *}$ & $\begin{array}{l}118,1602^{* *} \\
5,4 \text { anos }\end{array}$ & $9,7109^{* *}$ & $10,4345^{* *}$ & $3,4047^{\mathrm{ns}}$ \\
\hline Inclinação & $16,0292^{* *}$ & $0,2587^{\mathrm{ns}}$ & $1,6890^{\mathrm{ns}}$ & $10,9657^{* *}$ & $17,9312^{* *}$ & $1,5624^{\mathrm{ns}}$ \\
\hline Intersecção & $231,4300^{* *}$ & $49,1361^{* *}$ & $\begin{array}{l}129,7005^{* *} \\
6,3 \text { anos }\end{array}$ & $77,1983^{* *}$ & $57,2936^{* *}$ & $3,4365^{\mathrm{ns}}$ \\
\hline Inclinação & $19,0305^{* *}$ & $2,7671^{\mathrm{ns}}$ & $1,6538^{\mathrm{ns}}$ & $10,5940^{* *}$ & $18,4634^{* *}$ & $5,1452^{*}$ \\
\hline Intersecção & $184,9280^{* *}$ & $25,4386^{* *}$ & $\begin{array}{l}127,9685^{* *} \\
7,6 \text { anos }\end{array}$ & $97,6315^{* *}$ & $28,8569^{* *}$ & $17,8291^{* *}$ \\
\hline Inclinação & $0,0168^{\mathrm{ns}}$ & $0,9751^{\mathrm{ns}}$ & 0,4049 ns & 0,1452 ns & $0,0074^{\mathrm{ns}}$ & $0,2604^{\mathrm{ns}}$ \\
\hline Intersecção & $8,6460^{* *}$ & $4,5659^{*}$ & $10,4582^{* *}$ & $71,7205^{* *}$ & $2,2686^{\mathrm{ns}}$ & $30,7270^{* *}$ \\
\hline
\end{tabular}

Legenda: $\mathrm{ns}=$ não-significativo, $*=$ significativo a $5 \%, * *=$ significativo a $1 \% \mathrm{e}$ Test $=$ testemunha. 
Esse efeito é bem visualizado na Figura 10, em que as linhas de regressão se apresentaram muito próximas, podendo-se concluir que o fator densidade também não afetou a relação hipsométrica desse sítio nessas idades.

Brandi, Couto e Paula Neto (1977), trabalhando com Eucalyptus urophylla em Minas Gerais, verificaram
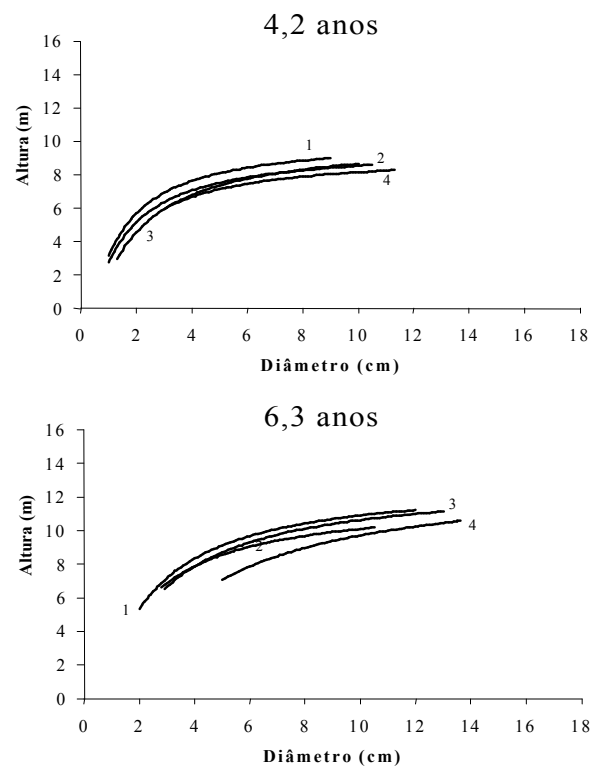

Legenda: (1) Testemunha, (2) 8.000, que houve efeito da densidade na relação hipsométrica. Os resultados obtidos por esses autores foram similares aos encontrados na maioria das combinações de sítio e idade do presente trabalho. Usando o teste qui-quadrado, verificaram não haver diferença significativa entre as linhas de regressão, que, em um mesmo diâmetro, em densidades (espaçamentos) diferentes, apresentaram alturas semelhantes.
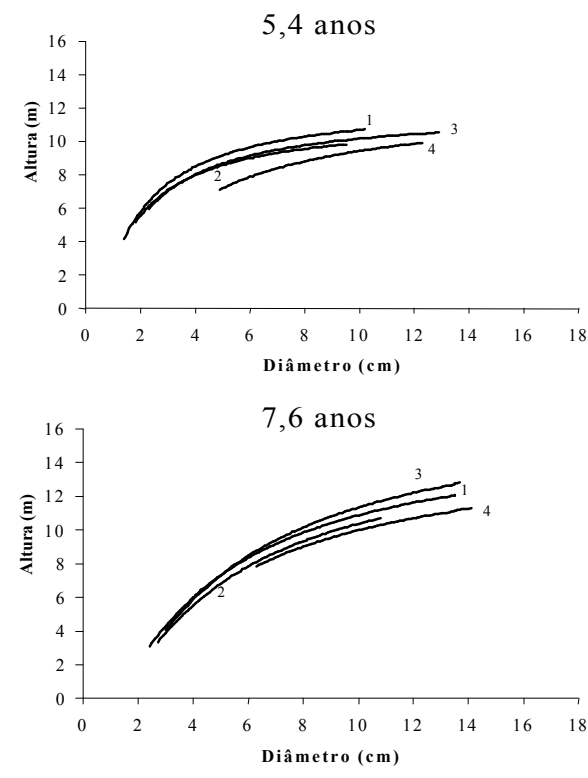

(3) $4.000, \quad$ (4) 2.000 árvores $/ \mathrm{ha}$

Figura 10 - Curvas hipsométricas do sítio III e nas idades de 4,2 a 7,6 anos, nos quatro tratamentos de densidade inicial Figure 10 -Height-diameter curves, on site III, from 4.1 to 7.5 year-olds for the 4 initial density treatments

\section{CONCLUSÕES}

Com base nos estudos realizados, pôde-se chegar às seguintes conclusões:

Os fatores idade e sítio afetaram a relação hipsométrica. O fator densidade não apresentou efeito de forma pronunciada na maioria dos conjuntos de curvas.

Com relação à idade, as curvas de altura são mais íngremes nas idades mais jovens, porém sobem suavemente nas parcelas mais velhas e se deslocam para a direita.

Em locais mais produtivos ( $\mathrm{IS}=16,8 \mathrm{~m})$, a inclina- ção das curvas foi ligeiramente mais acentuada do que nos locais menos produtivos ( $\mathrm{IS}=10,2 \mathrm{~m}$ ).

As curvas se movem para cima, das menores para as maiores densidades. As densidades-testemunha e 8.000 árvores/ha são consideradas similares, estatisticamente, nos sítios I e II.

\section{REFERÊNCIAS BIBLIOGRÁFICAS}

AZEVEDO, C.P., et al. Relação hipsométrica para quatro espécies florestais em plantio homogêneo e em diferentes idades na Amazônia ocidental.

Boletim de Pesquisa Florestal, n. 39, p. 5-29, 1999.

R. Árvore, Viçosa-MG, v.28, n.4, p.517-533, 2004 
BARTOSZECK, A.C.P.S. Evolução da distribuição diamétrica e da relação hipsométrica em função dos fatores idade, sítio e densidade inicial em bracatingais da região metropolitana de Curitiba. 2000. 214 f. Dissertação (Mestrado em Ciências Florestais). Universidade Federal do Paraná, Curitiba, 2000.

BAGGIO, A.J. Estudio sobre el sistema agroforestal tradicional de la bracatinga (Mimosa scabrella Benth.) en Brasil: productividad, manejo de residuos y elaboracion de compost . 1994. 242 f. Tese (Doutorado em Ingenieria de Montes). Escuela Técnica Superior de Ingenieros de Montes, Madrid, 1994.

BRANDI, R.M.; COUTO, L; NETO, F.P. Influência do espaçamento na sobrevivência, freqüência por classe de diâmetro e relação hipsométrica alturadiâmetro do Eucalyptus urophylla. Revista Ceres, v. 24, n. 136, p. 617-627, 1977.

BUFORD, M.A. Height-diameter relationships at age 15 in loblolly pine seed sources. Forest Science, v. 32, n.3, p. 812-818, 1986.

CARDOSO, D.J. Avaliação da influência dos fatores sítio, idade, densidade e posição sociológica na relação hipsométrica para Pinus taeda nas regiões central e sudoeste do Estado do Paraná. 1989. 106 f. Dissertação (Mestrado em Ciências Florestais). Universidade Federal do Paraná, Curitiba, 1989.

CARPANEZZI, A.A.; CARPANEZZI, O.T.B.; BAGGIO, A.J. Manejo de bracatingais In: CURSO DE MANEJO FLORESTAL SUSTENTAVEL, 1997, Curitiba. Tópicos em manejo florestal sustentável. Colombo: EMBRAPA-CNPF, 1997. p. 157-163.

CURTIS, R. O. Height diameter and height diameter age equations for second growth Douglas-fir. Forest Science, v. 13, n. 4, p. 365$375,1967$.

CRECHI, E.H. Efeitos da densidade da plantação sobre a produção, crescimento e sobrevivência de Araucaria angustifolia (Bert.) O. Ktze. em Missiones, Argentina. 1996. 172 f. Dissertação (Mestrado em Ciências Florestais). Universidade Federal do Paraná, Curitiba, 1996.

R. Árvore, Viçosa-MG, v.28, n.4, p.517-533, 2004
FIGUEIREDO FILHO, A. Estudos de modelos matemáticos para estimar o volume por unidade de área em uma floresta tropical úmida na Amazônia Brasileira. 1983. 150 f. Dissertação (Mestrado em Ciências Florestais). Universidade Federal do Paraná, Curitiba, 1983.

FREESE, F. Métodos estatísticos elementares para tecnicos forestales . Buenos Aires: Centro Regional de Ayuda tecnica; Agencia para el desarrollo internacional (AID) Mexico, 1970. 105 p (Manual da Agricultura, 317).

HAMMER, G.L. Site classification and tree diameter-height-age relationships for cypress pine in the Top End of the Northern Territory.

Australian Forestry. v. 44, n. 1, p. 35-41, 1981.

INSTITUTO AGRONÔMICO DO PARANÁ IAPAR. Cartas climáticas do Estado do Paraná: 1994. Londrina: 1994.

KOZAK, A. A simple method to test parallelism and coincidence for curvilinear regressions. In: IUFRO, CONFERENCE ADVISORY GROUP OF FOREST STATISTICIANS, 3., Jouy-en-Josas (France). Procedures... Paris: Institute National Recherche Agriculture, 1972. p. 133-145.

MAACK, R. Geografia física do Estado do Paraná. 2 ed. Rio de Janeiro: J. Olympio; Curitiba: Secretaria de Cultura e do Esporte do Governo do Estado do Paraná, 1981. 450 p.

MACHADO, S.A.; BASSO, S.F.; BEVILACQUA Jr, V.G. Teste de modelos matemáticos para o ajuste da relação hipsométrica em diferentes sítios e idades para plantações de Pinus elliottii no Estado do Paraná. In: CONGRESSO FLORESTAL PANAMERICANO, 1., CONGRESSO FLORESTAL BRASILEIRO,7., Curitiba, 1995. Anais... São Paulo: Sociedade Brasileira de Silvicultura, 1993. v 2, p. 553-556.

MACHADO, S.A. et al. Análise do comportamento da relação hipsométrica com respeito à idade para plantações de Pinus elliotti no Estado do Paraná. Cerne, v.1, n. 1, p. 5-12, 1994.

MACHADO, S.A. et al. Classificação de sítio para bracatingais na região metropolitana de Curitiba. Boletim de Pesquisa Florestal, n. 35, p. 21-37, 1997. 
NOWAK, D.J. Height-diameter relations of maple street trees. Journal of Arboriculture, v. 16, n. 9, p. 231-235, 1990.

OLIVEIRA, Y.M.M.; OLIVEIRA, E.B.; HAFLEY, W.L. Classificação de sítio para povoamento de Pinus taeda no sul do Brasil. In: CONGRESSO FLORESTAL BRASILEIRO, 6., 1990. Campos do Jordão. Anais... Campos do Jordão: 1990. p. 357-361.

OMULE, S. A. Y.; MCDONALD, R. N.

Simultaneous curve fitting for repeated heightdiameter measurements, Canadian Journal of Forestry Research, v. 21, n. 9, p. 1418-22, 1991.
PRODAN, M. et al. Mensura forestal. San José, Costa Rica: IICA, 1997. 586 p. (Serie Investigación y Educación en Desarrollo Sostenible).

SCHIMDT, P. B. Determinação indireta da relação hipsométrica para povoamentos de Pinus taeda L. 1977. 102 f. Dissertação (Mestrado em Ciências Florestais). Universidade Federal do Paraná, Curitiba, 1977.

TONON, A.E.N. Efeitos da densidade inicial e do sítio sobre o crescimento e a produção de bracatingais da Região Metropolitana de Curitiba . 1998. $209 \mathrm{f}$. Dissertação (Mestrado em Ciências Florestais). Universidade Federal do Paraná, Curitiba, 1998. 